International Journal of Technology 12(1) 139-148 (2021)

Received July 2020 / Revised August 2020 / Accepted January 2021

\title{
Computational Method for Designing a Nozzle Shape to Improve the Performance of Pico-Hydro Crossflow Turbines
}

\author{
Warjito $^{1}$, Budiarso ${ }^{1}$, Kevin Celine ${ }^{1 *}$, Sanjaya Baroar Sakti Nasution ${ }^{1}$ \\ ${ }^{1}$ Department of Mechanical Engineering, Faculty of Engineering, Universitas Indonesia, Kampus UI Depok, \\ Depok 16424, Indonesia
}

\begin{abstract}
The nozzle in a crossflow turbine is important because it accelerates the flow of the inlet and directs it to the runner at an angle relative to entrance angle $\left(\beta_{1}\right)$, which is used to obtain the maximum efficiency value. The $\beta 1$ value must match the angle of the runner's outer blade considering the transfer of water from stationary to the rotating coordinates. To obtain the desired $\beta 1$ value, the design of the nozzle is essential. In this study, 6-DoF simulations were conducted to find the best nozzle geometry. The incoming flow angles $(\lambda)$ of the nozzle ranged from $50^{\circ}$ to $90^{\circ}$. A study without a proper nozzle design was also conducted to compare the results. The results showed that a nozzle geometry of $\lambda=50^{\circ}$ yielded the highest efficiency $(60.6 \%)$. This study shows that the design of the nozzle in a crossflow turbine significantly affects its performance.
\end{abstract}

Keywords: Computational fluid dynamic; Crossflow turbine; Nozzle shape; Pico-hydro

\section{Introduction}

The In 2018, Indonesia's overall electrification percentage (the percentage of electrified households) was 98.3\%. However, in remote areas such as East Nusa Tenggara, it was only $62.07 \%$ (Ministry of Energy and Mineral Resources of the Republic of Indonesia, 2018). This is due to the demographic and geographic characteristics of remote areas. Remote areas have small, low-income populations and difficult transportation access. To meet the energy demands of remote areas and to accelerate the generation of renewable energy to meet the target of 66\% by 2050 (International Renewable Energy Agency, 2017), it is necessary to increase the use of renewable energy resources. Currently, the most widely used renewable energy is hydropower (Kaygusuz, 2010), and Indonesia has many water resources (Asian Development Bank, 2016).

Pico-hydro is a hydropower plant that generates electricity on a scale of less than $5 \mathrm{~kW}$ (Paish, 2002). Pico-hydro crossflow turbines, which have tubular runners with two discs (Sinagra et al., 2014), are suitable for remote areas that require small amounts of electricity. They have high efficiency and long life spans and are economical and environmentally friendly (Adanta et al., 2018b). Other advantages are their simple design and easy manufacture (Warjito et al., 2019).

In designing a crossflow turbine, one of the most critical components besides the blade is the nozzle (Chichkhede et al., 2016). The nozzle must be able to direct the flow so that it is properly distributed and the angle of flow matches the angle of the blade inlet $\left(\beta_{1}\right)$ 
(Adhikari and Wood, 2017). To obtain the desired flow conditions, the inlet discharge angle $(\lambda)$ is an important parameter.

Adanta et al. (2018b) designed and manufactured a crossflow turbine. However, their experimental results showed that the turbine had low efficiency. This is because in the design process, they only focused on calculating the geometry of the blade, whereas the nozzle geometry was not taken into account. Therefore, this study aimed to redesign the nozzle for Adanta et al. (2018b) turbine based on Sammartano et al. (2013), who reported efficiency of $82 \%$.

\section{Methods}

\subsection{Analytical Method}

This study compared three cases (cases 1,2, and 3) of nozzle geometry with the same blade geometry. The blade and runner geometries in all three cases were the same because the aim was to enhance turbine performance by optimizing only the nozzle design (Adanta et al., 2018b). The specific design parameters are shown in Table 1.

Table 1 Design parameters

\begin{tabular}{lccc}
\hline \multicolumn{1}{c}{ Design parameter } & Case 1 & Case 2 & Case 3 \\
\hline Number of blades $(\mathrm{z})$ & 20 & 20 & 20 \\
Outer radius (Rout) & $90 \mathrm{~mm}$ & $90 \mathrm{~mm}$ & $90 \mathrm{~mm}$ \\
Inner radius (R $)$ & $58.5 \mathrm{~mm}$ & $58.5 \mathrm{~mm}$ & $58.5 \mathrm{~mm}$ \\
Blade's length $(\mathrm{L})$ & $142 \mathrm{~mm}$ & $142 \mathrm{~mm}$ & $142 \mathrm{~mm}$ \\
Blade's inlet angle $\left(\beta_{1}\right)$ & $51^{\circ}$ & $51^{\circ}$ & $51^{\circ}$ \\
Angle of attack $\left(\boldsymbol{\alpha}_{\boldsymbol{i 1}}\right)$ & $22^{\circ}$ & $22^{\circ}$ & $22^{\circ}$ \\
Incoming flow angle $(\boldsymbol{\lambda})$ & $50^{\circ}, 60^{\circ}, 70^{\circ}, 80^{\circ}, 90^{\circ}$ & $50^{\circ}, 60^{\circ}, 70^{\circ}, 80^{\circ}, 90^{\circ}$ & - \\
\hline
\end{tabular}

To calculate the complete geometry parameters of the nozzle (Figure 1) based on known parameters, such as discharge and height, the outer diameter of the runner, the angle of attack, and the blade's length, the following equations were used Sammartano et al. (2013):

$$
\begin{gathered}
S_{0}=\lambda \sin \left(\alpha_{i 1}\right) R_{\text {out }} \\
\gamma=\arctan \left(\frac{S_{0} \sin \left(\alpha_{i 1}\right)}{R_{\text {out }}+\operatorname{Soc} \cos \left(\alpha_{i 1}\right)}\right) \\
\mathrm{S}_{0} \sin \left(\alpha_{i 1}\right)=\mathrm{r} \sin (\gamma)
\end{gathered}
$$
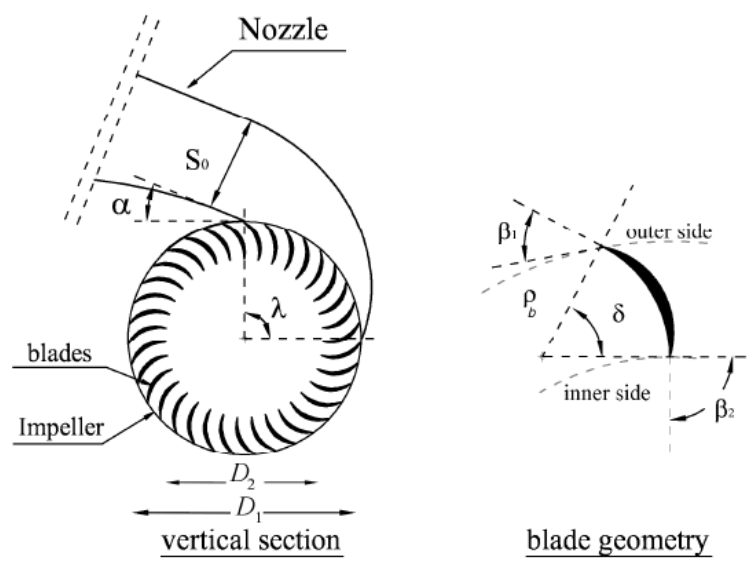

Figure 1 Geometry of the nozzle (Sammartano et al., 2013) 
The three cases differed in the shape of the nozzle. The geometry of the nozzle in case 1 was calculated based on Equations 1-3 (for details, see Sammartano et al., 2013), where the lambda value ranged from $50^{\circ}$ to $90^{\circ}$. Case 2 had a similar geometry to case 1 with slight modifications. The inlet height of the entry channel of the nozzle was made parallel to the top of the nozzle channel (Figure 2). This design was made to simplify the manufacturing process. In case 3, the nozzle was designed without considering the lambda value. An incoming flow angle was not assigned to the nozzle. The nozzle was straight, and the angle of attack of the initial turbine design was not taken into account. This is the geometry of the nozzle used in the Laboratory of Fluid Mechanics of Universitas Indonesia. The geometry of the nozzles is shown in Figures 2 and 3.

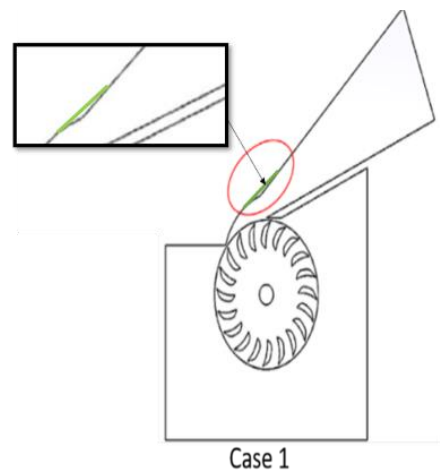

Figure 2 Nozzle geometry difference between cases 1 and 2

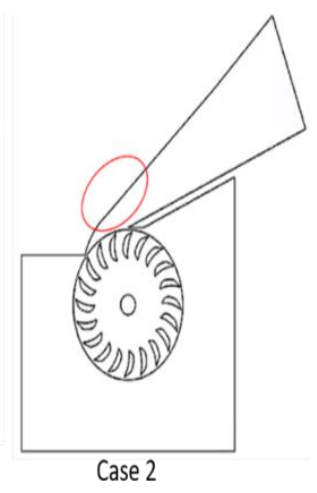

Figure 3 Nozzle geometry in case 3

\subsection{Computational Method}

The simulations were conducted in the 2D model using Ansys Fluent 18.1. The standard $\mathrm{k}-\varepsilon$ turbulent model was chosen due to its high accuracy of backflow and rotational flow (Gunadi et.al.,2018; Zhao et al., 2019). The boundary conditions were mass flow inlet and pressure outlet at the outlet. Mass flow was chosen because the AMG solver of Ansys Fluent works better with this than with other parameters (Ansys Fluent, 2011). Mass flow inlet on the boundary conditions was set to $90.8 \mathrm{~kg} / \mathrm{s}$ with total pressure of $0 \mathrm{~Pa}$ and pressure outlet of $0 \mathrm{~Pa}$ at the outlet. The boundary conditions are shown in Figure 4.

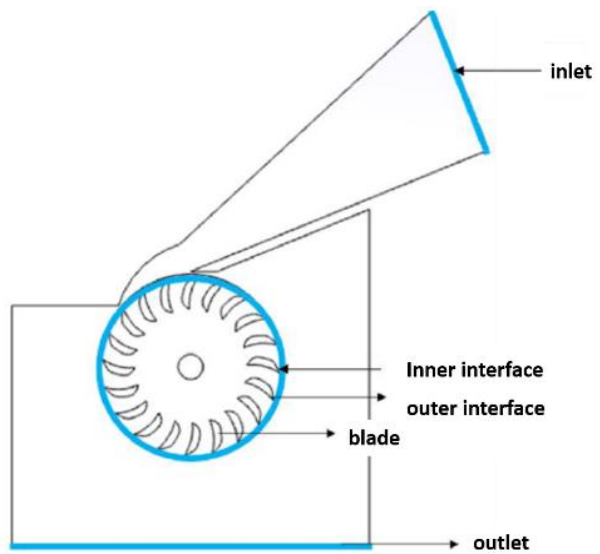

Figure 4 Boundary conditions

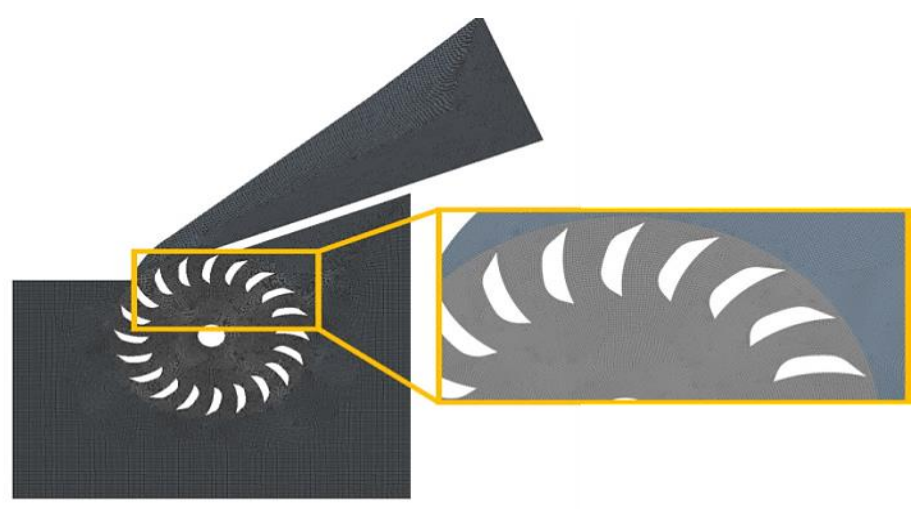

Figure 5 2D domain mesh visualization (106456 elements)

A dynamic mesh with six degrees of freedom (6-DoF) was used in this study. The 6-DoF feature was chosen because it can portray the physical and dynamic occurrence on the crossflow turbine impeller (Adanta et al., 2018a; Warjito et al., 2019). In a 6-DoF simulation, 
the preload needs to be determined. The preload in this study was $-7.04 \mathrm{~N} \mathrm{~m}$. This value was scaled according to the ratio of the actual blade length $(142 \mathrm{~mm})$ to the simulated blade length $(1000 \mathrm{~mm})$. The moment of inertia used was $0.03 \mathrm{~kg} \mathrm{~m}^{2}$.

\subsection{Mesh and Time Step Independence}

Mesh independence was achieved by refining the mesh size. The mesh numbers used were $23445,45227,88681$, and 104456 . The exact torque value was estimated using the Richardson extrapolation method (Phillips and Roy, 2014). The results showed that the appropriate mesh number was 104456 with an error of $1.77 \%$ (Table 2). Furthermore, as previously noted, a k- $\varepsilon$ turbulent model was used. The $\mathrm{k}-\varepsilon$ turbulent model requires a $\mathrm{y}+$ value of 30-300 (Frank et al., 2010). The average y+ value in this study was 40.5. The mesh visualization is shown in Figure 5.

Table 2 Mesh independence test results

\begin{tabular}{ccc}
\hline Number of elements & Torque $(\mathrm{N} \mathrm{m})$ & Grid convergence index \\
\hline 23445 & 2.771 & $9.25 \%$ \\
45227 & 2.983 & $7.37 \%$ \\
88681 & 3.097 & $3.86 \%$ \\
106456 & 3.220 & $1.77 \%$ \\
$\sim$ & 3.221 & \\
\hline
\end{tabular}

With the same method, four different values were used for the time step size (Table 3). A value of 0.001 was chosen, as it had the lowest convergence value (2.8\%).

Table 3 Time step independence test results

\begin{tabular}{ccc}
\hline Time step size & Torque $(\mathrm{N} \mathrm{m})$ & Time step convergence index \\
\hline 0.002 & 0.986 & 0.086 \\
0.001 & 0.987 & 0.028 \\
0.0005 & 0.988 & 0.035 \\
0 & 0.990 & - \\
\hline
\end{tabular}

\section{Results and Discussion}

\subsection{Analytical Results}

Table 4 shows the results of the nozzle geometry for each $\lambda$ value calculated with Equations 1, 2, and 3. The results showed that the wider the angle $\lambda$, the greater the geometry of the nozzle.

Table 4 Analytical results of the nozzle geometry with each $\lambda$ value

\begin{tabular}{cccccc}
\hline$R_{\text {out }}(\mathrm{m})$ & $\alpha\left(^{\circ}\right)$ & $\mathrm{S}_{\text {o }}(\mathrm{m})$ & $\lambda\left(^{\circ}\right)$ & $\mathrm{r}(\mathrm{m})$ & $\gamma\left({ }^{\circ}\right)$ \\
\hline 0.09 & 22 & 0.053 & 90 & 0.146 & 8.12 \\
0.09 & 22 & 0.047 & 80 & 0.135 & 7.52 \\
0.09 & 22 & 0.041 & 70 & 0.129 & 6.86 \\
0.09 & 22 & 0.035 & 60 & 0.123 & 6.15 \\
0.09 & 22 & 0.029 & 50 & 0.118 & 5.37 \\
\hline
\end{tabular}

\subsection{Numerical Results}

To calculate the efficiency value, the following equation was used: 


$$
\eta=\frac{\tau \times \omega}{\rho g Q H} \times 100 \%
$$

where $\tau$ is torque in the blade $(\mathrm{N} \mathrm{m}), \omega$ is the rotational speed, $\rho$ is the density of water, $g$ is gravitational acceleration, $Q$ is the water discharge speed, and $H$ is the head height.

3.2.1. Variation of $\lambda$ in case 1

The comparison of the efficiency to U/V ratios in case 1 is shown in Figure 6. $U$ is the tangential velocity of the runner, and $\mathrm{V}$ is the absolute entrance velocity.

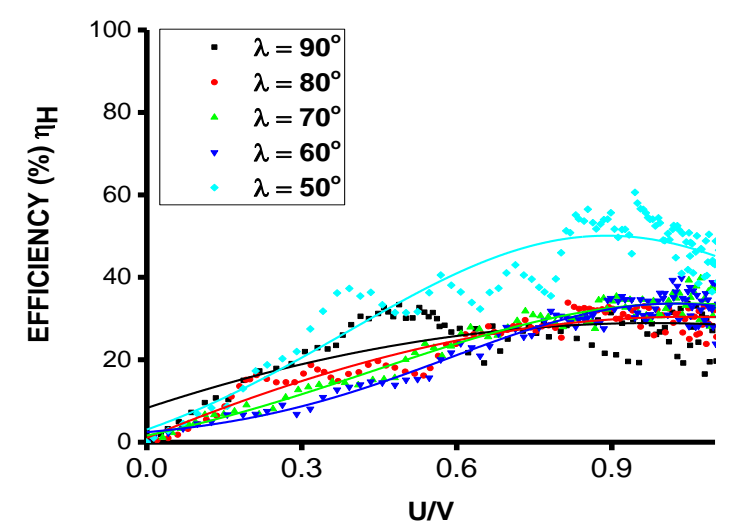

Figure 6 Efficiency to $U / V$ ratios of different nozzle $\lambda$ values in case 1

The value of $\lambda=50^{\circ}$ yielded the highest efficiency (60.6\%). The maximum efficiency values achieved with $\lambda=60^{\circ}, \lambda=70^{\circ}, \lambda=80^{\circ}$, and $\lambda=90^{\circ}$ were $49.19 \%, 42.7 \%, 36.66 \%$, and $40.41 \%$, respectively.

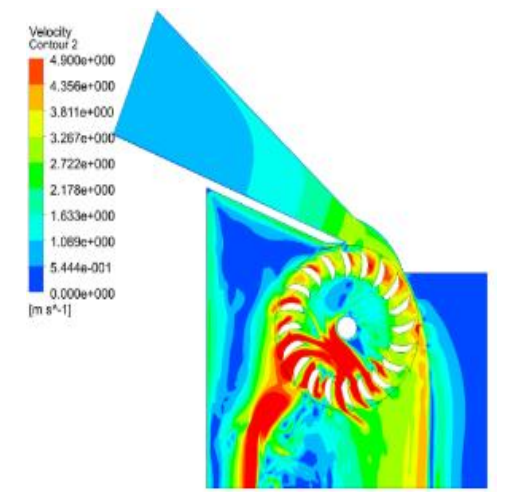

$\lambda=50^{\circ}$

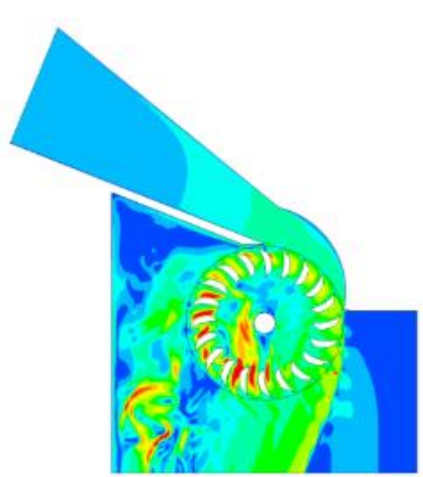

$$
\lambda=80^{\circ}
$$

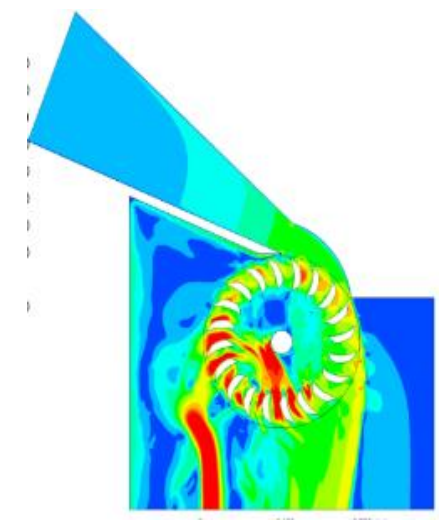

$\lambda=60^{\circ}$

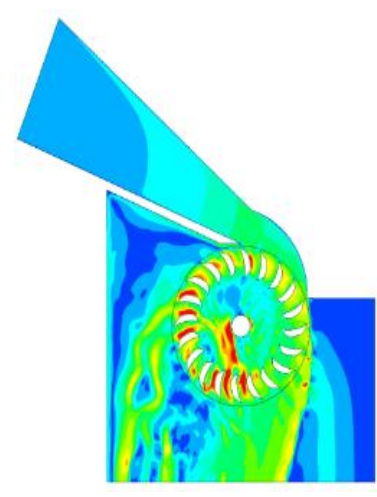

$\lambda=70^{\circ}$

Figure 7 Velocity contour in case 1 
The observed efficiency fluctuation was due to the use of the 6-DoF method. Unlike the motion mesh and Multi Reference Frame (MRF) methods, in which the rpm values remain constant, the 6-DoF method shows different rpm values in each time step, depending on the power absorbed on the blade. The velocity contour is shown in Figure 7 . The value of $\lambda=$ $50^{\circ}$ produced the highest velocity. This is one of the reasons that the nozzle with $\lambda=50^{\circ}$ had the highest efficiency.

\subsubsection{Variation of $\lambda$ in case 2}

In case 2 , as in case 1 , the value of $\lambda=50^{\circ}$ resulted in the highest efficiency $(43.21 \%)$. The maximum efficiency values achieved with $\lambda=60^{\circ}, \lambda=70^{\circ}, \lambda=80^{\circ}$, and $\lambda=90^{\circ}$ were $35.32 \%, 32.88 \%, 33.15 \%$, and $26.81 \%$, respectively. As shown in Figures 8, the patterns observed in case 2 were similar to those observed in case 1 . A reduction in $\lambda$ caused an increase in velocity in the blade inlet area (Figures 9). The reduced area caused this at the end of the nozzle. The velocity increase at the blade inlet yielded the highest efficiency with the value of $\lambda=50^{\circ}$. Previous studies have shown that decreasing the value of $\lambda\left(120^{\circ}\right.$ to $90^{\circ}$ ) increases turbine efficiency (Nakase et al., 1982; Fiuzat and Akerkar, 1989, 1991). Moreover, Khosrowpanah suggested that a high value of $\lambda$ should not be used in cases of a nozzle without a guide vane (Khosrowpanah et al., 1988).

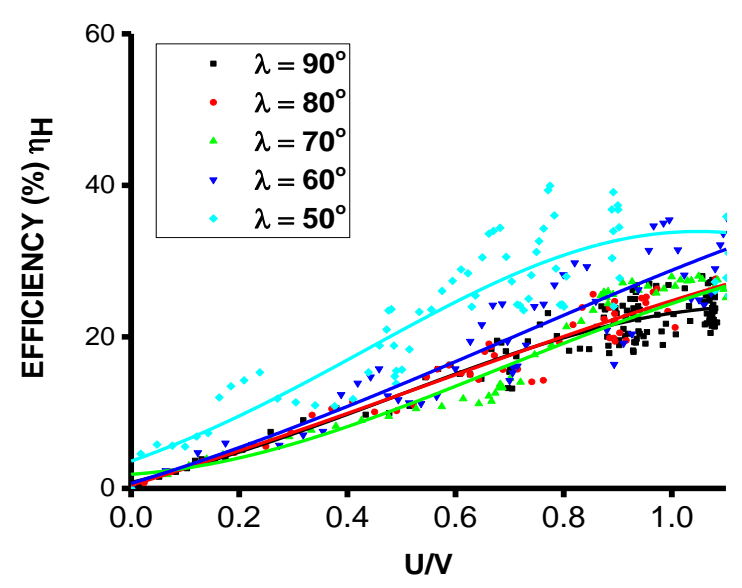

Figure 8 Efficiency to $U / V$ ratios of different nozzle $\lambda$ values in case 2

Figure 9 shows the velocity contour in case 2 .

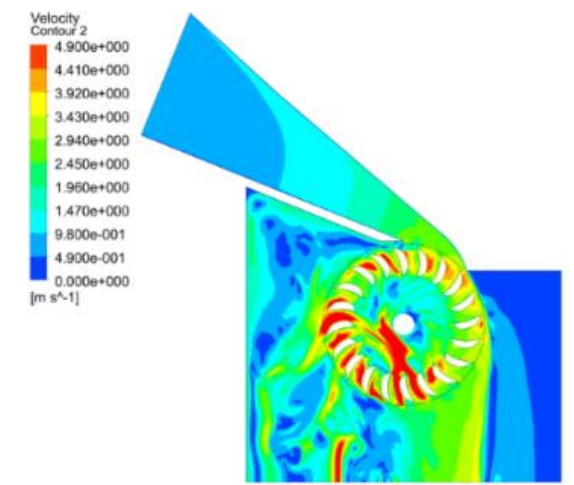

$\lambda=50^{\circ}$

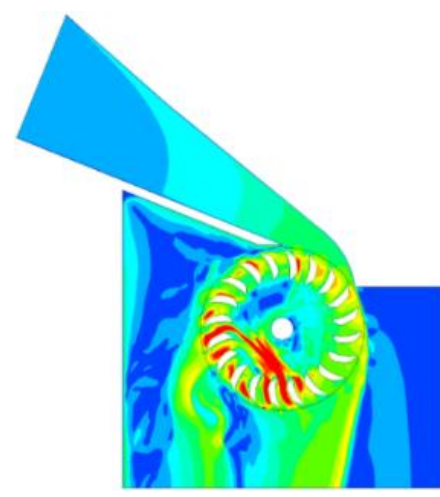

$\lambda=60^{\circ}$

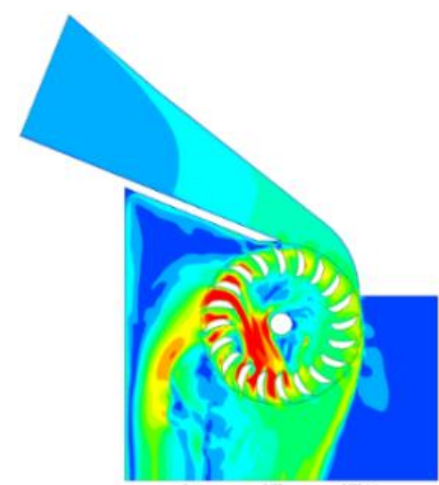

$\lambda=70^{\circ}$ 

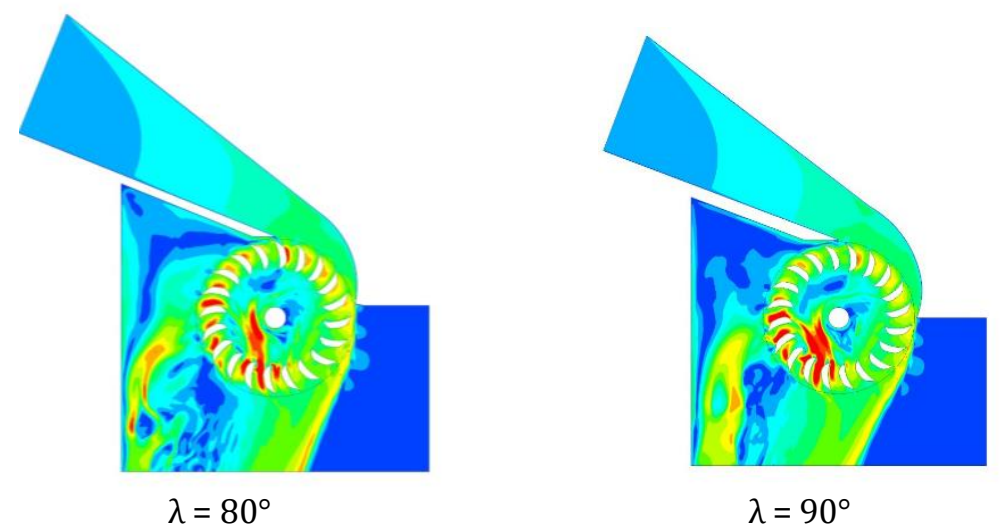

Figure 9 Velocity contour in case 2

\subsection{Comparison of Cases 1, 2, and 3}

As shown from the comparisons in Table 5, the modifications of the nozzle affected the performance of the crossflow turbine. Case 1 had the highest efficiency (61\%), followed by case $2(43 \%)$ and case $3(7 \%)$. In cases 1 and 2, the highest efficiency was obtained with a $\mathrm{U} / \mathrm{V}$ ratio of 1.2 and $\lambda=50^{\circ}$.

Table 5 Comparison of cases 1, 2, 3 and Adanta (2020) experiment

\begin{tabular}{cccc}
\hline Case & Max $\lambda$ & Max U/V & Max Eff \\
\hline Case 1 & $50^{\circ}$ & 1.2 & 0.61 \\
Case 2 & $50^{\circ}$ & 1.2 & 0.43 \\
Case 3 & - & 0.6 & 0.07 \\
Adanta (2020) experiment & - & 0.8 & 0.08 \\
\hline
\end{tabular}

For validation, the simulation results were compared with the experimental results of Adanta in his studies (Adanta, 2020). The experiment was performed using a turbine with a geometry identical to the computational conditions of case 3 . The experiment was conducted in a head height condition of $2.1 \mathrm{~m}$ and discharge of $0.0128 \mathrm{~m}^{3} / \mathrm{s}$ with peak mechanical efficiency of $8.45 \%$ (Adanta, 2020).

Figures 10 and 11 show the distribution of water velocity shortly before the water hits the blade. Figures $10 \mathrm{a}, \mathrm{b}$, and c show the velocity vectors, while Figure 11 shows the flow velocity at the blade inlet and the incidence angle of the flow. The incidence angle was obtained based on the difference between the flow and blade angles. The values $\mathrm{i}$ and $\mathrm{V}$ represent the incidence angle and velocity magnitude on the blades. The position of data collections are shown in Figure 10d.

As shown in Figures 10a-10b and Figure 11, the arch on the roof of the nozzle affected the velocity magnitude of water flow. The velocity magnitude at the flow field of the blade entry in case 1 was higher than in case 2. However, as shown in Figure 11, the incidence angle in case 2 was greater than in case 1 . Therefore, the efficiency of the turbine in case 1 was higher than in case 2. These results are consistent with Adhikari and Wood (2017), who reported that the shape of the rear wall, albeit small, affects the performance of the crossflow turbine. 


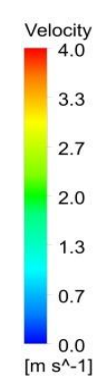

$\left[\mathrm{m} \mathrm{s} \mathrm{s}^{\wedge}-1\right.$

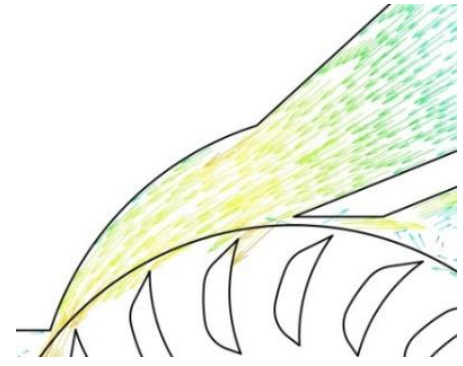

(a)

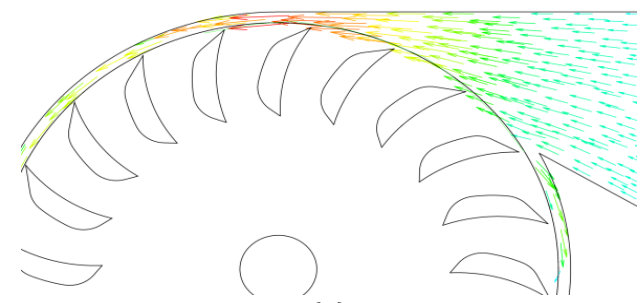

(c)

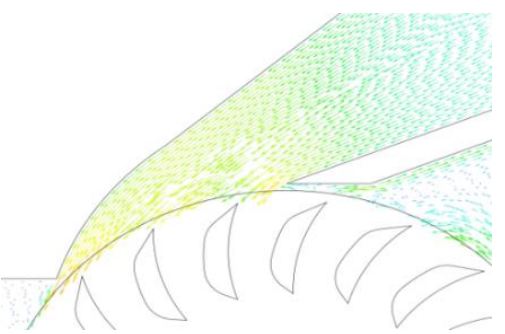

(b)

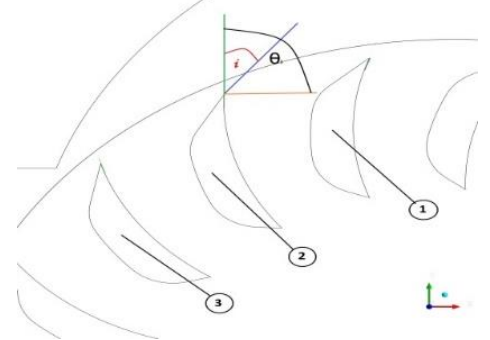

(d)

Figure 10 Velocity vector: (a) Case $1\left(\lambda=50^{\circ}\right)$; (b) Case $2\left(\lambda=50^{\circ}\right)$; and (c) Case 3. (d) Incidence angle

The same phenomenon was observed in case 3. As shown in Figure 11, the velocity magnitude in case 3 was higher than in cases 1 and 2, but the turbine efficiency was the lowest (7\%). This was due to the high incidence angle in case 3 (Figure 11). The height of the incidence angle and its effect on blade efficiency are consistent with Lewis (1996), who suggested that the incidence angle on the blade should not be zero but not too wide either, as that causes a loss.

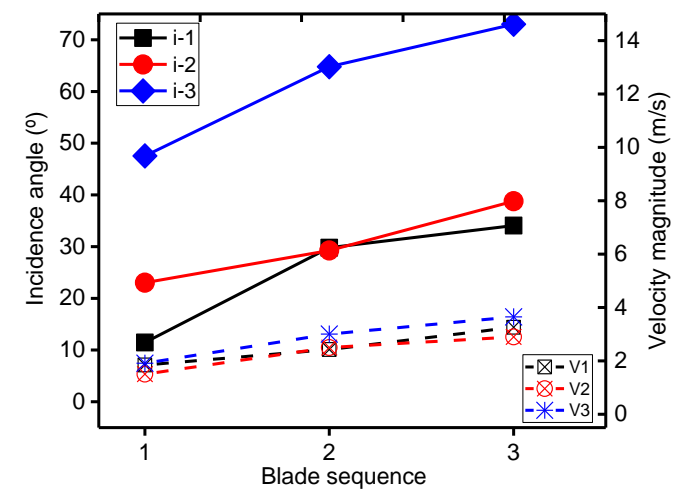

Figure 11 Incidence angle (i) and velocity magnitude (V) at the inlet blade

Additionally, the incidence angle increased from blade 1 to blade 3 in all three cases (Figure 11). This suggests that the shape of the nozzle cannot change the direction of water flow optimally (see velocity vector in Figures $10 \mathrm{a}, 10 \mathrm{~b}$, and 10c). It can thus be concluded that the difference in turbine efficiency between cases 1,2 , and 3 is closely related to the incidence angle at the inlet blade, which is related to the nozzle shape. Therefore, the design of the crossflow turbine nozzle should take into account the ability of the nozzle to change the flow angle in the direction of the blade angle. 


\section{Conclusions}

In this study, the optimal angle $\lambda$ of the nozzle in cases 1 and 2 was $50^{\circ}$. The highest efficiency was obtained in case $1(60.6 \%)$. This study shows that the design of the nozzle in a crossflow turbine greatly affects its performance.

\section{Acknowledgements}

This work was supported by the Ministry of Research, Technology, and Higher Education (KEMENRISTEK DIKTI) of the Republic of Indonesia with grant number NKB2959/UN2.RST/HKP.05.00/2020.

\section{References}

Adanta, D., 2020. Investigasi Konstanta bachelor dan Kolmogorov Model Turbulen k -e Standard untuk Turbin Piko Hidro Jenis Crossflow (Investigation of the Constant of Bachelor and Kolmogorov on Standard k-epsilon Turbulence Model for Cross-Flow PicoHydro Turbine). Doctoral Dissertation. Universitas Indonesia

Adanta, D., Budiarso, Warjito, Siswantara, A.I., Prakoso, A.P., 2018a. Performance Comparison of NACA 6509 and 6712 on Pico Hydro Type Cross-Flow Turbine by Numerical Method. Journal of Advanced Research in Fluid Mechanics and Thermal Sciences, Volume 45(1), pp. 116-127

Adanta, D., Hindami, R., Budiarso, Warjito, Siswantara, A.I., 2018b. Blade Depth Investigation on Cross-flow Turbine by Numerical Method. In: The $4^{\text {th }}$ International Conference on Science and Technology (ICST), Yogyakarta, Indonesia, pp. 1-6

Adhikari, R.C., Wood, D.H., 2017. A New Nozzle Design Methodology for High Efficiency Crossflow Hydro Turbines. Energy for Sustainable Development, Volume 41, pp. 139148

ANSYS Fluent, 2011. Ansys Fluent Theory Guide. ANSYS Inc: Canonsburg

Asian Development Bank, 2016. Indonesia Country Water Assessment. ISBN 978-92-9257360-7 (Print), 978-92-9257-361-4 (e-ISBN). Mandaluyong, Philippines

Chichkhede, S., Verma, V., Gaba, V.K., Bhowmick, S., 2016. A Simulation Based Study of Flow Velocities across Cross Flow Turbine at Different Nozzle Openings. Procedia Technology, Volume 25, pp. 974-981

Fiuzat, A.A., Akerkar, B., 1989. The Use of Interior Guide Tube in Cross Flow Turbines. In: Waterpower 1989: Proceedings of the International Conference on Hydropower, Niagara Falls, NY, USA, pp. 21-26

Fiuzat, A.A., Akerkar, B.P., 1991. Power Outputs of Two Stages of Cross-Flow Turbine. Journal of Energy Engineering, Volume 117(2), pp. 57-70

Frank, T., Lifante, C., Prasser, H.-M., Menter, F., 2010. Simulation of Turbulent and Thermal Mixing in T-Junctions using URANS and Scale-Resolving Turbulence Models in ANSYS CFX. Nuclear Engineering and Design, Volume 240(9), pp. 2313-2328

Gunadi, G.G.R., Siswantara, A.I., Budiarso. 2018. Turbulence Models Application in Air Flow of Crossflow Turbine. International Journal of Technology, Volume 9(7), pp. 1490-1497

International Renewable Energy Agency, 2017. Renewable Energy Prospects: Indonesia. Avalaibale Online at https://www.irena.org//media/Files/IRENA/Agency/Publication/2017/Mar/IRENA_R Emap_Indonesia_report_2017.pdf, Accesed on July 15, 2020

Kaygusuz, K., 2010. Renewable Energy: Power for a Sustainable Future. Energy Exploration \& Exploitation, Volume 19(6), pp. 603-626

Khosrowpanah, S., Fiuzat A.A., Albertson M.L., 1988. Experimental Study of Cross-Flow 
Turbine. Journal of Hydraulic Engineering, Volume 114(3), pp. 299-314

Ministry of Energy and Mineral Resources of the Republic of Indonesia, 2018. Electrification Ratio. Jakarta, Indonesia

Nakase, Y., Fukatomi, J., Watanaba, T., Suetsugu, T., Kubota, T., Kushimoto, S., 1982. A Study of Cross-flow Turbine (Effects of Nozzle Shape on its Performance). In: Proceedings of the ASME $103^{\text {rd }}$ Winter Annual Meeting, Phoenix, AZ, USA, pp. 14-19

Paish, 0., 2002. Small Hydro Power: Technology and Current Status. Renewable and Sustainable Energy Reviews, Volume 6(6), pp. 537-556

Phillips, T.S., Roy, C.J., 2014. Richardson Extrapolation-based Discretization Uncertainty Estimation for Computational Fluid Dynamics. Journal of Fluids Engineering, Volume 136(12), https://doi.org/10.1115/1.4027353

Sammartano, V., Aricò, C., Carravetta, A., Fecarotta, O., Tucciarelli, T., 2013. Banki-Michell Optimal Design by Computational Fluid Dynamics Testing and Hydrodynamic Analysis. Energies, Volume 6(5), pp. 2362-2385

Sinagra, M., Sammartano, V., Aricò, C., Collura, A., Tucciarelli, T., 2014. Cross-Flow Turbine Design for Variable Operating Conditions. Procedia Engineering, Volume 70, pp. 15391548

Warjito., Budiarso., Kevin, C., Adanta, D., Prakoso, A.P., 2019. Computational Methods for Predicting a Pico-Hydro Cross-Flow Turbine Performance. CFD Letters, Volume 11(12), pp. 13-20

Zhao, G., Li, W., Zhu, J., 2019. A Numerical Investigation of the Influence of Geometric Parameters on the Performance of a Multi-Channel Confluent Water Supply. Energies, Volume 12(22), pp. 1-21 